\title{
Leandro Fernández de Moratín, su casa de Pastrana y el círculo de sus amigos ilustrados
}

Esther Alegre Carvajal

Universidad Nacional de Educación a Distancia (UNED)

CES.XVIII, núm. 17 (2007), págs. 41-63. 
Resumen: Los conocidos vínculos familiares de Leandro Fernández de Moratín con la villa alcarreña de Pastrana, así como la casa de descanso que construyó en ella, son el hilo conductor que permite analizar y aportar novedades sobre este capítulo de su vida. El artículo estudia la íntima relación del dramaturgo con el arquitecto Silvestre Pérez, autor del proyecto general de esta casa y supervisor de su ejecución; cómo llegaron a ella, invitados por Moratín, muchos de los afrancesados de su círculo más cercano; y cómo la relación afectiva y cordial que Moratín muestra hacia Pastrana a lo largo de su vida se transforma tras la guerra: su recuerdo se convierte en amargo y su casa en una pesada carga. Sin embargo, hasta el final de sus días mantiene un vínculo sentimental, casi jovial, con la villa gracias a la afable camaradería con Luisa, oriunda de Pastrana, y amante de su fraternal amigo Juan Antonio Melón.

Palabras clave: Leandro Fernández de Moratín. Pastrana. Silvestre Pérez. Juan Antonio Melón. Afrancesados. Francisco Fernández Beteta. Luisa Gómez Carabaño. 
Leandro Fernández de Moratín, hijo del también dramaturgo Nicolás Fernández de Moratín, nació en Madrid el 10 de marzo de 1760 y murió en París el 21 de junio de 1828. Fue, sin lugar a dudas, el comediógrafo más destacado de su época, aunque su pluma no olvidó la lírica, a la que contribuyó bajo el pseudónimo de Inarco. El estudio de la figura de Moratín, de su vinculación con Pastrana, de sus relaciones amistosas y amorosas, y de su correspondencia, no sólo nos acerca al espíritu del dramaturgo, a su carácter y a sus sentimientos, también al de la convulsa época que le tocó vivir. La relación de Moratín con la villa alcarreña fue larga y estrecha, aunque no exenta de desengaños y sentimientos enfrentados.

Grandes fueron la ilusión y el empeño que Leandro Fernández de Moratín puso en su casa de Pastrana, en la que disfrutó de la compañía de su círculo de amistades y en la que pasó agradables temporadas. Sin embargo, estos primigenios sentimientos sufrieron una inexorable transformación a causa de la agitada situación política que vivía España, en especial tras la adhesión de Moratín al bando bonapartista, que tendría evidentes consecuencias posteriores durante la guerra de la Independencia.

Sobradamente conocidas son las raíces de Moratín en Pastrana:

Mi abuelo paterno era Jefe de Guardajoyas de la reina viuda, doña Isabel de Farnesio; llamábase don Diego Fernández de Moratín, era natural de Madrid; y su mujer, doña Inés González Cordón, había nacido en Pastrana, de honrada familia de labradores propietarios [...]. Mi abuela tenía en Pastrana dos hermanas y un hermano, canónigo y Dignidad de aquella Iglesia $[\ldots]^{1}$.

Su padre, Nicolás Fernández de Moratín, pasaba largas temporadas en la Alcarria y se puede suponer que también él las pasó en su niñez y pubertad. Aunque sobre estas primeras estancias juveniles no hay noticias tan precisas como sobre las de su madurez, registradas con brevedad en su Diario, sí se puede aventurar que su relación con Pastrana era intensa debido a los estrechos lazos

1 Leandro Fernández de Moratín, Obras póstumas, Madrid, M. Rivadeneyra, 1867-1868, t. III, pág. 301. Curiosamente, el tío abuelo de Moratín era Pedro González Cordón, canónigo de la colegiata, que según el Catastro del Marqués de la Ensenada (AмP, sig. 223, ff. 106 v.-111 r.), tenía una casa en la plaza de los Cuatro Caños. 
familiares $^{2}$ que le ligaban con la villa. Sirva como ejemplo la inocente nota, escrita con tanta espontaneidad, que aparece en su Diario el 29 de marzo de 1782, cuando trabajaba en el obrador de joyería de su tío: «fuese Águeda a Pastrana [...]»³.

La atenta lectura de su Diario y de su Epistolario confirma que, contrariamente a lo que había sido habitual, estuvo seis años — tal vez siete — sin visitar Pastrana, desde 1791, fecha en la que recibió el beneficio de Montoro, abandonó el obrador de su tío y en la que se convirtió en secretario personal de Cabarrús.

La protección de Manuel Godoy, por su parte, fue decisiva en la vida del dramaturgo. Gracias a esta, entre 1792 y 1796, pudo realizar una serie de viajes por Europa que le permitieron entrar en contacto con las últimas tendencias teatrales y le alejaron de su querida Pastrana.

Según se desprende de las misivas del crítico napolitano Signorelli, varias son las cartas que ya en 1791 no llegaron a manos de su destinatario en Pastrana, probablemente a causa de estos viajes. En la primera de ellas leemos:

Mi estimado Leandro: A su apreciable carta del día 12 de mayo de 1791 [la misiva a la que hace referencia no ha podido ser localizada] tuve buen cuidado de responder con otra mía en 20 de junio, la envié a mi hijo para que la dirigiera a Pastrana $[\ldots]$.

Con fecha 26 de marzo de 1792 le escribe: «que aquella y otras [cartas] mías y ajenas se extraviaron $[\ldots]{ }^{4}$.

En 1796, de vuelta a España, obtuvo el cargo de secretario de Interpretación de Lengua, lo que le aportaba un desahogo económico considerable. A este nombramiento se unió, tres años más tarde, el de director de la Junta de Dirección y Reforma de los Teatros, con el que se inicia para el literato una etapa de prosperidad, simultánea a sus momentos de mayor creatividad teatral, que culmina en 1806 con el estreno de El sí de las niñas.

Es en este tiempo, sin duda el mejor en la vida de Leandro Fernández de Moratín, cuando se intensifican sus nexos con Pastrana, de la que había estado ausente en los años de su periplo europeo.

2 Moratín mantuvo siempre fuertes vínculos familiares, incluso se hizo cargo de su tío Miguel y de sus hijos, Mariquita y Gumersindo, debido a sus escasos medios económicos. Su querida tía Anita, a la que visitaba con frecuencia, estaba casada con Victoriano Galeoti, joyero como los otros miembros de la familia de Moratín. No se ha podido verificar el origen italiano de Galeoti, pero sí la existencia en Pastrana, en 1752, de una familia apellidada Galeote: Manuel, Francisca y María.

3 Leandro Fernández de Moratín, Diario, Madrid, Castalia, 1968, pág. 67.

4 «Carta a L. F. de Moratín» (Nápoles, 26 de marzo de 1792), en Eugenio Hartzennusch, Bibliografía de Hartzenbusch, Sucesores de Rivadeynera, 1900, t. II, pág. 123. 
Poseer una casa de descanso en la que retirarse de la corte fue una idea muy meditada por Moratín. Ya en 1794, estando en Bolonia (Italia), escribió a su querido amigo Juan Antonio Melón «Si en primavera hubiesen mudado las cosas y hallase una porción segura de ir a España lo haría no por otra cosa que buscar un rincón en la Alcarria donde vivir la mitad del año [...]» ${ }^{5}$. Este deseo se convirtió pronto en realidad.

Tres años más tarde, entre el 11 y el 27 de octubre de 1797 —escasamente un año después de haber adquirido su vivienda de la calle Silva de Madrid-, días en los que recibió la visita de un presbítero de la iglesia colegial de Pastrana, evidentemente gran amigo suyo ${ }^{6}$, su intención de tener un lugar en la Alcarria en el que evadirse toma una forma concreta: una casa en Pastrana. Su amigo Melón lo relata así:

Quiso comprar una hacienda en Linares (se trata de Linares de Riofrío), provincia de Salamanca, donde yo tengo algunas, y quería que fuésemos allá los veranos; pero le disuadí [...]. Pero un Canónigo de Pastrana, menos mirado, le metió en que comprase una mala casa de aquella Iglesia y edificase allí otra $[\ldots]^{7}$.

Pese a tan malicioso comentario, conociendo los deseos del autor, se puede suponer que al presbítero no le costó ningún esfuerzo convencerlo.

Es a partir de aquí cuando nuestro comediógrafo establece contactos constantes con personas vinculadas a Pastrana hasta que, por fin, realiza la visita en la cual decide adquirir la propiedad. Así, el 13 de noviembre recibe, por primera vez, a Teresica, con quien posteriormente compartiría tantas tardes en Pastrana; el 22 de noviembre se entrevistó con Antonio Jabonero Ruiz y don P. Herrera ${ }^{8}$, vecinos de Alcalá de Henares. Como es habitual, no anota en su Diario el motivo de la entrevista, pero podemos adivinar que sirvió para organizar sus traslados a Pastrana puesto que es en el domicilio de Herrera, en Alcalá de Henares, donde hace escala en sus posteriores desplazamientos a la villa. Tanto a la ida como a la vuelta anotó en su Diario: «[...] chez Don P. Herrera, ubi souper and sleep [...]». Del mismo modo, con el doctor Jabonero, dignidad de la magistral de Alcalá y rector del Colegio de Málaga, abordó cuestiones relativas a su viaje a Pastrana.

5 Eulalia Castellote, «La casa de Pastrana (recuerdo de Leandro Fernández de Moratín)», en WadAl-Hayara, núm. 5 (1978), págs. 209-217 (pág. 210).

6 En su Diario, Moratín lo recoge en varias notas. El 11 de octubre escribe: «venit Presbítero ici hospedado»; el 27 del mismo mes anota: «fuese Presbítero». La familiaridad que se advierte en esta relación constata esos intensos vínculos familiares con Pastrana.

7 Castellote, «La casa de Pastrana», págs. 210-211.

8 Fernández de Moratín, Diario, pág. 193. 
Moratín conocía a Jabonero de antaño, como natural de Pastrana9 ${ }^{9}$ y lo visitaba en cada una de las paradas que hacía en Alcalá. Fue precisamente en el domicilio de Mariquita Jabonero ${ }^{10}$, pariente del magistral, donde se alojó Moratín en sus primeras estancias en la villa hasta que pudo hacerlo en el suyo propio.

Posteriormente, en tres ocasiones —el 22 de diciembre de 1797, el 15 de enero y el 7 de febrero de 1798_-, visitó a Antonio Taravillo, a quien, según sus propios papeles, planteó cuestiones sobre la casa de Pastrana ${ }^{11}$.

Por fin, el 16 de febrero se trasladó a Pastrana acompañado de un íntimo amigo, tal vez para pedirle consejo; se trata de José Antonio Conde ${ }^{12}$, académico, historiador y arabista, bibliotecario de El Escorial y, antes que el propio Moratín, de la Biblioteca Real de Madrid (con el tiempo, al casarse este con Mariquita, la sobrina y protegida de Moratín, recibió como regalo de boda la casa de Pastrana). Ambos hicieron escala en Alcalá de Henares y al día siguiente llegaron a Pastrana ${ }^{13}$.

Este viaje fue definitivo para que Moratín decidiese la compra de la casa y el terreno contiguo a ella. La determinación del dramaturgo de adquirir una pequeña explotación agrícola, no sólo una casa con jardín, es clara. Durante su breve estancia visitó con interés las huertas ajardinadas ${ }^{14}$ existentes en el casco urbano: «[...] Casa de Morales and horta [...]» y «[...] Horta del Duc [...]»; es decir, el palacio de la familia Burgos, del siglo XVII, junto a su jardín y huerta ${ }^{15}$,

9 Había nacido en Pastrana el 8 de junio de 1742. Casi con toda seguridad era hermano, o pariente muy próximo, de Bartolomé Jabonero Ruiz, rico comerciante de seda, Manuel Jabonero Ruiz, labrador rico, y Francisco Jabonero Ruiz (vid. AMP, Catastro del Marqués de la Ensenada, sig. 223, ff. 106 v.-111 r.).

10 En la relación de Moratín con Mariquita podría haber algo más que un mero vínculo de hospedaje. Si en el primer viaje se refiere a ella en los términos «Señora María veuve ("viuda") de Jabonero» (se trata de uno de los hermanos de Antonio Jabonero Ruiz, vid. nota anterior), ahora ha pasado a ser Mariquita Jabonero, tratamiento extraño para las rigurosas y protocolarias relaciones dieciochescas.

11 En su Diario (pág. 194, nota 528, y págs. 196-197): «chez (“en casa de”) Taravillo».

12 Nacido en Peraleja (Cuenca) en 1765, era amigo íntimo de Moratín, en cuyo Diario aparece en continuas ocasiones. Estudió en Cuenca y Alcalá y fue bibliotecario de El Escorial y, más tarde, de la Biblioteca Real de Madrid. Eminente historiador, fue un gran estudioso de la España musulmana. Perteneció al grupo de afrancesados que formó parte del gobierno de José I, en el que ocupó el cargo de jefe de división del Ministerio del Interior.

13 Diario, pág. 198: «ad 4 Complutum; chez don P. Herrera, ubi souper, sleep»; «ad 6 in Paterniana; chez Señora María veuve de Jabonero, ubi hospedaje».

14 En Esther Alegre Carvajal y Tomás Nieto Taberné, Los jardines de Pastrana, Guadalajara, aache Ediciones, 1997, se estudia pormenorizadamente este tipo de explotación agraria como una de las variantes de los jardines moriscos; allí se definen como «fincas rústicas, enclavadas a cierta distancia del casco urbano, con extensión suficiente y condiciones precisas para una explotación intensiva hortofrutícola, sobre la base de agua abundante, recogida y distribuida mediante estanques y canales, y reforzada, en los sistemas de cultivo, por una tradición que se ha convertido en costumbre».

15 Se trata de la casa de don Juan Francisco de Burgos y Morales (vid. Esther Alegre Carvajal, La Villa Ducal de Pastrana, Guadalajara, AACHE Ediciones, 2003, págs. 198 y ss., donde se estudian detalladamente el palacio y la huerta). 
y la huerta del Duque, unida al denominado palacio Viejo ${ }^{16}$, ambas modelos de inspiración para la magnífica huerta-jardín que se llevaría a cabo en la casa de Moratín y que le permitieron conocer y valorar la dimensión y el tipo de explotación agrícola que podría realizar en su posesión.

En esta primera visita, Moratín apenas permaneció en Pastrana ocho días, pero su decisión estaba tomada. El 28 de febrero, al día siguiente de su regreso a la Corte, a juzgar por el orden en su Diario, a primera hora de la mañana visitó al arquitecto Silvestre Pérez ${ }^{17}$, a quien había conocido en Italia, donde este había estado pensionado por la Real Academia de San Fernando entre 1792 y 1796, y con quien había entablado una gran amistad que duraría el resto de su vida ${ }^{18}$. Es fácil deducir que le relató pormenorizadamente lo que había visto y que le comunicó su resolución y sus planes. Seis días después, el 6 de marzo de 1798, compró la casa ${ }^{19}$, por la que pagó 17.000 reales.

Pérez, como amigo íntimo y como arquitecto, se había convertido, tras su vuelta a Madrid, en su consejero más cercano en cuanto a la adquisición y reforma de sus propiedades inmuebles. Ya a principios de 1797 le había asesorado sobre la vivienda que este había adquirido en la calle Silva (el dramaturgo anotó en su Diario indicaciones muy similares a las que posteriormente registraría sobre su casa de Pastrana: el 20 de febrero de 1797, «Casa nova cum Pérez [...]»; el 23 del mismo mes, «casa nova / pase, promenade cum Don Silvestre Pérez [...]»; el 24 de febrero, «ici Pérez; cum \& $\&^{a}$ casa nova [...]»; o el 2 de marzo, «ici Pérez / casa nova $\left.[\ldots]^{20}\right) »$.

Después, ya instalado Moratín en su nueva morada madrileña de la calle Silva, las reuniones entre ambos se dilataron en el tiempo; se visitaban una vez al

\footnotetext{
16 Ibid., págs. 117 y ss.

17 Nació en Epila (Zaragoza) en 1767. Discípulo de Antonio Sanz, en 1781 se trasladó a Madrid, donde se convirtió en colaborador de Ventura Rodríguez y fue protegido por el círculo de los ilustrados. Terminados sus estudios en la Academia de San Fernando, entre 1792 y 1796 residió en Roma como pensionado. Fue allí donde conoció a Leandro Fernández de Moratín. De vuelta a Madrid, fue nombrado profesor de arquitectura. Su primera gran obra es la iglesia parroquial de Motrico (1798), a la que siguió el proyecto del nuevo Bilbao o Puerto de la Paz (1807). Tras la llegada del nuevo rey, José Bonaparte, Pérez pasó a formar parte del grupo de los afrancesados. Como arquitecto del rey, realizó el primer proyecto de la puerta de Toledo y una reestructuración de Madrid, que no se llevarían a cabo. En 1813 salió de España con el grupo de los afrancesados, aunque dos años más tarde ya estaba de vuelta. Con Ugartemendía como ayudante, trabajó en el País Vasco, donde ejecutó obras como el Teatro de Vitoria o el Ayuntamiento de San Sebastián. Otros proyectos, como la plaza Nueva o el Ayuntamiento de Bilbao, no llegaron a realizarse. Murió en 1825.

18 El 23 de marzo de 1794 aparece por primera vez en su Diario (pág. 122), a partir de este momento son continuas las referencias a Pérez, tanto en el Diario como en el Epistolario.

19 Previamente, el 1 de marzo, visita de nuevo a Antonio Taravillo (Diario, pág. 199). En la nota que corresponde a aquel día se puede leer: «ici Dean Paternianae». En su Epistolario (pág. 567) se recoge una carta, fechada en septiembre de 1823 y dirigida a García de la Prada, en la que afirma: «[...] Por la compra de ella pagué en Madrid al Deán el día seis de marzo de 98 [...] 17.000» (BNM, ms. 7664).

20 Diario, págs. 179-180.
} 
mes, incluso no tuvieron contacto alguno a lo largo de tres meses ${ }^{21}$. Sin embargo, cuando el proyecto de la casa de Pastrana (otra «casa nova») tomó cuerpo, su relación con Pérez se vivificó y volvió a hacerse casi diaria.

El desarrollo de los acontecimientos políticos hizo que Moratín regresara a la villa con prontitud. El 28 de marzo se produjo la primera caída de Godoy y el dramaturgo salió apresuradamente de Madrid camino de Pastrana.

Aunque fue este un viaje precipitado que sirvió a Moratín para huir de la capital ante la desgracia del valido, sin embargo, también parece que había sido organizado previamente ya que con él acudió Silvestre Pérez.

El 30 de marzo, desde Alcalá de Henares, Moratín, junto a su también amigo Francisco Fernández Beteta y Silvestre Pérez, sale para Pastrana: «a 8 cum Pérez y Beteta sortir; / a 6 in Paterniana [...]» ${ }^{22}$. A lo largo de esta estancia, que se prolongaría hasta el 15 de abril, el arquitecto tomó las medidas de la vivienda (cada día aparece anotado en el Diario del escritor: «cum Pérez, Casa nova, medir [...]»), dio las indicaciones oportunas a los canteros encargados del trabajo ( «cum Pérez y Cobo ${ }^{23}$ ad Casa nova [...]») y, junto al operario encargado de la obra, visitó diferentes casas para estudiar qué era lo que se podía hacer («cum Presbítero, Pérez y Francisco López ${ }^{24}$, videre Casas $[\ldots]^{25}$ )».

Indudablemente fue Silvestre Pérez quien asesoró, quien ideó y quien realizó los planos de la nueva casa. Además, fue él quien resolvió el problema fundamental de la edificación, la construcción del muro de contención y el relleno de una parte del terreno del barranco sobre el que se iba a asentar la nueva vivienda. El problema era de considerable envergadura, por lo que en el siguiente viaje de Moratín, en abril y mayo de 1799, llegó con él un contingente de trabajadores enviados específicamente por Silvestre Pérez para llevar a cabo las reformas: «Ofizial Benedictus a Pérez misso venit [...] ${ }^{26}$, «Carpinteros quos Pérez missit venerunt $[\ldots]{ }^{27}$. El propio Silvestre Pérez llegó para inspeccionar las obras el 16 de mayo: «Pérez venit [...]»; tan sólo permaneció un día en Pastrana, el 17 de mayo, en el que Moratín exclusivamente anota «asa $[\ldots] »$.

${ }^{21}$ Según se desprende de su Diario, entre el 4 de abril y el 19 de julio no se reúne ni una sola vez con su amigo, presumiblemente Pérez estaba ausente de la capital por el encargo de la iglesia de Motrico.

22 Diario, pág. 200.

23 Juan Antonio Cobo, Maestro Cantero y Carpintero de esta Villa (12 de septiembre de 1800, AMP Libros de Actas 1800, sig. 35.2, sin foliar).

24 Jornalero encargado de las obras de Pastrana. En los siguientes viajes, Moratín trató con él con frecuencia.

25 Diario, pág. 201.

26 Ibid., pág. 219.

27 Ibid., pág. 220. 
A partir de aquí, la construcción sigue su curso, dirigida por el oficial Benedictus, operario de confianza de Silvestre Pérez y a quien este habría dado las instrucciones oportunas.

La intervención de Silvestre Pérez en la casa moratiniana de Pastrana no debe resultar sorprendente ${ }^{28}$ puesto que ambos eran íntimos amigos, mantenían una estrecha y constante relación y, en ese momento, todavía Pérez no había alcanzado el reconocimiento que obtendría posteriormente. Si con anterioridad lo había asesorado sobre su casa madrileña de la calle Silva, también lo haría después, en mayo de 1800, cuando mudara su domicilio capitalino; como recoge su Diario, Pérez acompañó a su amigo a verlo y le asesoró en su decisión «[...] chez Pérez; cum il casa de Calle San Mateo [...]» ${ }^{29}$.

Esta amistad, con altibajos, se mantuvo a lo largo de la azarosa vida de ambos; así, en los disturbios de mayo de 1808, cuando un nervioso Moratín iba y venía a casa de sus íntimos amigos, entre ellos se encontraba Silvestre Pérez. Posteriormente, tras la guerra de la Independencia y la dispersión de los afrancesados, su relación se pudo mantener gracias al contacto de Juan Antonio Melón con el arquitecto. El dramaturgo, en su correspondencia con su incondicional Melón, muestra un constante interés y afecto por su amigo Pérez. Así, en las misivas remitidas a aquel (Barcelona, 21 de agosto de 1821; Burdeos —donde se había instalado definitivamente-, 20 de enero y 2 de febrero de 1822) leemos: «Dale a Pérez mi cordial enhorabuena por su ascensión; yo me he alegrado [...]» o «Dile a Pérez que quisiera una noticia relativa a los académicos de San Fernando que han sido borrados de la lista [...]».

Tras el viaje de mayo de 1799, Moratín volvió a Pastrana el 19 de septiembre y estuvo allí, con el fin de inspeccionar personalmente las obras, como anota repetidamente en su Diario, hasta el 18 de noviembre. Ese mismo día volvió con él a Madrid el oficial Benedictus, hecho del que se colige que el escritor permaneció en Pastrana hasta que el núcleo más importante de la obra fue terminado.

En su visita del 2 de septiembre de 1800, la obra ya está concluida, por lo que le acompañan las Muñoz: Paquita, la que entonces parecía que podría

28 Ninguno de los estudiosos de la figura de Moratín, así como tampoco los de Silvestre Pérez, han señalado este hecho, ni siquiera como mera curiosidad, pese a que en esta época Pérez estaba preocupado por el problema arquitectónico de la relación del individuo con la naturaleza y con lo que se ha denominado «construcciones mínimas» (vid. Carlos SAmbricio, La arquitectura española de la Ilustración, Madrid, Consejo Superior de los Colegios de España de Arquitectos de España-Instituto de Estudios de Administración Local, 1986, pág. 224).

29 Diario, pág. 239. Moratín gustaba de mudar de casa, sin embargo, en los cambios posteriores ya no estuvo acompañado de su amigo. En su Diario se percibe un enfriamiento en la relación o al menos cierta distancia. Volvieron a reunirse, pero no con la asiduidad que lo habían hecho, entre los años 1797 y 1800. 
llegar a ser su esposa y a la que cortejó durante largos años, y la madre de esta ${ }^{30}$. Es entonces cuando por primera vez se instala en su casa y anota en su Diario la emoción del momento: «[...] ad 8 Paterniana, in casa nova, ubi spectantes Teresica, Beteta, Presbitero, $\&^{a}[\ldots]{ }^{31}$. A partir de ese momento, Moratín acudió a su cita con Pastrana cada año. El 24 de agosto de 1801 volvió y se marchó el 28 de septiembre, en esta ocasión no lo acompañó Paquita. Por lo que se desprende de sus notas hubo un disgusto entre ellos: «Ego triste $[\ldots] »$, «...] littera Pacita [...]». Parece que en julio de ese año Moratín concluyó El sí de las niñas y es muy posible que su lectura — no hay que olvidar que la comedia desprende ciertos tintes autobiográficos — provocara el enfado de Paquita, lo que explicaría su ausencia y las notas del Diario $^{32}$.

El 10 de septiembre de 1802 inició otra de sus asiduas temporadas en Pastrana, que se alargaría hasta el 18 de octubre; esta vez acudió acompañado de Vicente Sarriá, amigo y esposo de su prima Antonia ${ }^{33}$. Volvió, solo, el 12 de agosto de 1803. Días más tarde, el 3 de septiembre, llegó Juan Antonio Loche, escritor y editor, uno de sus amigos íntimos: «[...] cum ils (presbitero, Beteta y Teresica) ad corredera spectantes Loche, qui venit [...]» ${ }^{34}$. Ambos se marcharon el 8 de octubre.

En los años siguientes, 1804 y 1805, no acudió a su obligada cita con Pastrana (es posible que en 1804 no lo hiciera debido al estreno de La mojigata). Regresó el 4 de julio de 1806. Esta vez le acompañó el éxito de su teatro, de ahí que fuera recibido no sólo por sus amigos de siempre, sino por los miembros del ayuntamiento, que lo agasajaron de manera formal «[...] ici Decanus, Praetor, Antón, $\&, \&[\ldots]{ }^{35}$. En esta visita, que se prolongaría hasta el 5 de septiembre, ya no se hallaba el presbítero, aquel que le animara a comprar la casa y que tal vez había fallecido, aunque en el Diario no haya ninguna referencia explícita a su óbito.

Nuevamente residió en Pastrana en el estío de 1807, entre el 22 de junio y el 4 de septiembre.

30 Moratín conoció a Paquita Muñoz en mayo de 1798 gracias a su amigo Conde, que se hospedaba en casa de los padres de Paquita. Ella era casi una niña, tan sólo tenía dieciocho años. La relación entre ambos se intensificó, lo que hizo que, durante años, Paquita albergara ilusiones de una posible boda, nada más lejos de las intenciones de nuestro autor quien, al tiempo, mantenía relaciones con la actriz María García. Paquita se casó algunos años después, en 1816, con el militar Francisco Valverde (Fernando DoménEch, Leandro Fernández de Moratín, Madrid, Síntesis, 2003, págs. 131 y ss.).

31 Diario, pág. 244.

32 Refuerza esta hipótesis el hecho de que Moratín acostumbraba acudir a Pastrana en el mes de septiembre, incluso octubre, tan solo en esta ocasión lo hizo en agosto.

33 Sarriá murió a los pocos meses de haber acompañado a Moratín a Pastrana. Volvieron a Madrid el 18 de octubre y el 29 de diciembre de 1802 Moratín recoge en su Diario (pág. 283): «obiit Sarriå».

34 Diario, pág. 295.

35 Ibid., pág. 343. El Praetor es el alcalde mayor. En 1752, según el Catastro del Marqués de la Ensenada (AMP, sig. 223), eran alcaldes ordinarios «don Alphonso Franco y Soldado y Juan de Illana Herranz». 
Su último viaje lo realizó en 1808. No se sabe la fecha de su llegada, pero no es difícil suponer que sería pocos días después del Levantamiento, o tal vez antes. Tras la caída de Manuel Godoy en el Motín de Aranjuez — 17 al 19 de marzo de 1808-, con las tropas imperiales en la capital, la situación se hizo insostenible $^{36}$. La última anotación en el Diario del dramaturgo es del 24 de marzo de 1808: «[...] venit new King [...] vidi King [...]». Evidentemente se refiere a Fernando VII, que asumió el trono tras la abdicación de su padre. Para recuperar la corona, Carlos IV pide ayuda a Napoleón, que se convierte en árbitro del conflicto y ofrece una reunión entre padre e hijo en Bayona, donde ambos renuncian al trono. La situación creada en la capital, de total incertidumbre, estalla con el Levantamiento del dos de mayo.

La inquietud e inseguridad con que vive Moratín estos días son manifiestas. Los disturbios callejeros alteran su tranquilidad y le hacen temer por su vida; además, Godoy, su protector, es definitivamente desterrado a Francia. Aunque en estas fechas existen grandes lagunas en su Diario, sí se recoge la existencia de tropas en su propia casa «[...] nam ici hospites $[. ..]{ }^{37}$.

Ante esta situación, es lógico que Moratín decidiera abandonar Madrid y refugiarse en su hogar estival de Pastrana. Fue allí donde le sorprendieron los primeros acontecimientos de la guerra y donde tuvo lugar aquello que trasmutó sus sentimientos hacia la villa: su prendimiento. Este hecho fue determinante, una brecha se abrió en su relación afectiva con Pastrana y sus paisanos: el vínculo se había roto, nunca más volvería Moratín a Pastrana.

He aquí sus reflexiones sobre estos graves sucesos:

¿Qué puedes esperar de aquella gente bestial, que en el mes de junio del año ocho nos fue a buscar con podones y trancas al desierto de Bolarque, y reñía por la repartición de los diez mil reales que les habían de dar en Madrid, así que nos entregaran muertos o vivos $[\ldots]^{38}$ ?

En la actualidad apenas quedan restos de la casa de Moratín; es difícil imaginarla ya que, posteriormente y a lo largo de un siglo, cumplió las funciones de convento de diferentes órdenes religiosas y de colegio de niñas. No obstante, contamos con la inestimable descripción de Mesonero Romanos ${ }^{39}$, que intentó quedarse con ella en 1859:

36 El 19 de marzo, Carlos abdicó en su hijo, mientras Godoy era enviado preso al castillo de Villaviciosa. La noticia causó un gran entusiasmo en el pueblo que se echó a la calle y saqueó la casa del valido. Escenas semejantes se reprodujeron en muchas otras localidades del país.

37 Diario, pág. 374.

38 Leandro Fernández de Moratín, Epistolario, Madrid, Castalia, 1973, pág. 345.

39 Ramón de Mesonero Romanos, «Un viaje a Pastrana», en El Museo Universal (1 de abril de 1859). 
Es de bastante buena forma y capaz, con pisos bajo, principal y segundo; toda ella de cal y canto, con ventanas antepechadas y guarnecidas de sillería; la escalera y habitaciones son claras, espaciosas [...] Pero lo primero que choca al contemplar esta, es la mala elección del sitio en que se halla colocada; en el fondo de un barranco, sobre el cual hubo de colocarse un antepecho para defenderla de las aguas que en ocasiones descienden a torrentes del cerro contiguo [...] Su carácter sombrío, tímido y receloso (se refiere a Moratín) se ve también confirmado en la disposición interior de dicha casa; con fuertes puertas y cerrojos, que cuidaba de cerrar por sí mismo todas las noches antes de cobijarse en la última de dichas habitaciones, en la que además había hecho abrir una puerta de escape a la huerta [...].

Sin embargo, sí se ha conservado, con la misma disposición establecida por el dramaturgo, la huerta ${ }^{40}$. Moratín quiso tener una finca de recreo, pero también una explotación agrícola, y compró un terreno, extramuros de la población pero junto a ella, donde erigió una casona acompañada de una gran huerta.

Ésta, de grandes proporciones y limitada por el barranco descrito por Mesonero Romanos, se adapta a la topografía del terreno y desciende mediante suaves terrazas desde su límite oeste, hoy camino del cementerio ${ }^{41}$, hasta el este, el barranco; todas las terrazas están cultivadas como huerto. Anterior a ellas, en la zona más alta y presumiblemente unido a lo que fue la casa original por la «puerta de escape» ${ }^{42}$, se encontraba el primer recinto de jardín; por su altura, enlazaba con la parte superior de la casa, lo que permitía la contemplación del paisaje ${ }^{43}$ que se componía de una masa arbórea de nogales, granados y frutales del gusto del dramaturgo:

Hice traer de Madrid el tiesto de pita, y de él me han salido diez plantas que he ido distribuyendo por la huerta; crecerán y haré pulque para emborrachar a estos idólatras; pienso también traer chirimoyas y zapotes prietos, y chicos zapotes $[\ldots]^{44}$.

Unido a este recinto se encontraba el primer estanque en el que Moratín tomaba los baños tantas veces reseñados en su Diario; desde él arranca un paseo

40 Alegre Carvajal y Nieto Taberné, Los jardines de Pastrana, págs. 104-105.

${ }_{41}$ Es posible que la huerta fuera más extensa; parte del terreno sería cedido para hacer la comunicación con el cementerio, cuando este se construyó.

42 La incorporación de estas puertas falsas a las viviendas de Pastrana, tuvieran o no jardín, fue una aportación claramente morisca a la tipología de vivienda popular cristiana (vid. Alegre Carvajal, La Villa Ducal de Pastrana, pág. 207).

43 El que no perviva ningún resto de lo que fue la casa de los Moratín hace que nos movamos en el terreno de las hipótesis al señalar que el enlace de la casa con la huerta posiblemente se hiciera, como en el colegio de San Buenaventura, mediante un patio bajo. En la actualidad existe un patio con un gran muro de contención de tierras, presumiblemente original de la casa.

44 Epistolario, págs. 209-260. 
que recorre la huerta, formando una pérgola con emparrado a lo largo de toda su longitud que cumple una doble función: zona de servicios y de recreo. A mitad del paseo se abre una zona limitada de jardín, donde se sitúa otro estanque con masas de arbolado y velador; al final del mismo, otra zona de estancia con estanque. Al primero, a modo de pequeña terraza elevada, se accedía por unas escaleras; quedaba el nivel del agua del estanque a ras del suelo, como si se tratara de una lámina de agua. El situado al fondo de la huerta, donde terminaba el paseo, era un espacio con dos grandes nogales que daban una inmensa sombra sobre el estanque y el velador situado junto a él ${ }^{45}$ — cuenta la tradición que allí acudía el dramaturgo a escribir sus comedias-. Realmente, pese a lo que afirmaba su amigo Melón, es un jardín-huerta precioso.

Esta pasión por los jardines y el campo no abandonó nunca a Moratín. No sólo suscitaban en él gran interés las huertas urbanas existentes en la villa (la del Duque, las de los conventos, la del Colegio de San Buenaventura y otras particulares), que visitaba reiteradamente en cada uno de sus viajes («tour ad horta Colegii»; «horta ex tío Cañamares»; «horta Burgos»), y que, como ya se ha señalado, le sirvieron de inspiración para la suya propia, también su última casa en Madrid poseyó un hermoso jardín plantado y dispuesto por él mismo y, ya instalado en Burdeos, dio noticia a su amigo Melón sobre la excelente casa que habitaba y presumía de su jardín a la vez que señalaba, con vehemencia, que también disfrutaba de una casa en el campo donde pasar largas temporadas.

Al reclamo del comediógrafo, para disfrutar de su hospitalidad, de su amistad y de su conversación, acudían a la villa sus íntimos amigos, un eminente foco de ilustrados que, a partir de 1808, ya afrancesados, tomaría parte activa en el gobierno de José I Bonaparte ${ }^{46}$. Pastrana se convirtió en un referente para este círculo de amigos. Como ya se ha señalado más arriba, visitaron la villa el académico José Antonio Conde, el arquitecto Silvestre Pérez, cuya contribución en las obras de la casa fue fundamental, Vicente Sarriá, amigo de Moratín y esposo de la prima hermana Antonia, José Viera y Clavijo ${ }^{47}$, quien coincidió con Pérez

\footnotetext{
45 Las áreas de estanque y velador son propias de los jardines de tradición morisca pastraneros. Se encuentran en todos ellos, donde se combinan zonas de jardín con otras de huerto (vid. Alegre Carvajal y Nieto Taberné, Los jardines de Pastrana, págs. 67-70).

46 Todos los miembros del círculo moratiniano ocuparon destacados cargos dentro del gobierno josefino. José Antonio Melón fue jefe de división del Ministerio de Hacienda; José Antonio Conde, jefe de división del Ministerio del Interior; Moratín formó parte de la Comisión de Teatros y posteriormente fue nombrado bibliotecario mayor de la Biblioteca Nacional; Silvestre Pérez pasó a ser arquitecto del Ayuntamiento de Madrid; Antonio Pinto y Juan Antonio Loche, por su parte, también fueron significados afrancesados.

47 Conocido escritor e historiador canario perteneciente al círculo de amigos de Moratín. Viajó por Europa acompañando al marqués de Santa Cruz y es posible que tanto Moratín, como Silvestre Pérez, coincidieran con él en su periplo europeo. Murió en 1813, por lo que no sufrió la represión fernandina.
} 
en los días en que este se trasladó para vigilar las obras en $1799^{48}$ (Moratín no anotó que abandonara Pastrana con ellos, por lo que se puede suponer que tal vez él permaneció en ella algún tiempo más). En 1803 lo acompañó el editor Juan Antonio Loche y, tres años más tarde, llegó para pasar con él parte del verano su amigo Antonio Pinto, actor que había representado algunas de sus obras. El 16 de julio Moratín anotó en su Diario: «[...] ici Pinto venit $[\ldots]{ }^{49}$. Al año siguiente se repite la visita. El 2 de agosto de ese año apuntó en su Diario: «[...] spectans Pinto: venit; ici $[\ldots]{ }^{50}$.

Pero, sin duda y a pesar de que en el Diario apenas se hace referencia a él, si Moratín tuvo una amistad especial, esa fue la de Juan Antonio Melón, quien a la postre estuvo más cercano a Pastrana y quien lo acompañaba en aquel fatídico día de 1808 en que lo apresaron.

En la villa, Moratín pasaba su tiempo ocupándose de su casa y de su huerta, disfrutando de baños en su estanque, actividad que le proporcionaba un verdadero placer y, sobre todo, dando largos paseos por todos los parajes del término de Pastrana: «cum Beteta paseo»; «ad fons Locaya ("a la fuente Locaria o Locaya")»; «moulin of paper and Carmen ("al molino de papel y al convento del Carmen")»; «ad + Mirandae ("a la Cruz de Miranda")»; «ad Valdefuentes»; «cum il Calvario»; «Hocino»; «Val»; «paseo ad Melgar»; «ad Valdegatos», etcétera.

También acudía al palacio ducal («vidi palacio») y a las nuevas instalaciones que estaba realizando el duque del Infantado («vidi Palacio and tornos»; «ici Beteta; cum il, Palacio, vidi hilanderas»), incluso en algún momento gozó allí de su máxima afición («cum Beteta videre Teatro and Palais»; «vidi teatro, jardines and palacio»). Tampoco pasó por alto acercarse a la iglesia y contemplar sus tesoros («vidi reliquiae Ecclesiae, and sepulcra»—se refiere a la colección de reliquias que posee la colegiata y al panteón de los duques de Pastrana-). En diferentes ocasiones acudió a los conventos masculinos, el de carmelitas y el de franciscanos, que todavía no habían sido desamortizados, para disfrutar de sus bibliotecas («cum Beteta ad Carmen vidi Prior»; «ad San Francisco»; «Biblioteca»; «Enfermería»; «cum Beteta and Pinto, Carmen, ubi horta, hermitas, convent, reliquiae, \&, vidimus»). Incluso, pese a la distancia, paseaba hasta el convento franciscano del Desierto de Bolarque, el lugar donde lo prendieron.

Según se desprende de las anotaciones de su Diario, con frecuencia — asiduamente los domingos - y a primera hora de la mañana, acudía a la celebra-

48 Según el Diario (págs. 219-220), el 16 de abril de 1799 llegaron Moratín y Viera y, el 16 de mayo, Pérez.

49 Ibid., pág. 343.

$50 \quad$ Ibid., pág. 362. 
ción de la misa en la iglesia del convento de San Francisco, tan próxima a su casa, incluso en diversas ocasiones fue acompañado de sus amigos: «cum Sarriá ad San Francisco»; «cum Loche ad San Francisco». Y en alguna oportunidad asistió al canto del Salve Regina en la ermita de Santa Ana («ad Santa Ana, ubi Salve Regina»). Paradójicamente, aunque en sus estancias en Pastrana asistía a los oficios religiosos, no era así cuando se hallaba en la capital. Moviéndonos en el terreno de las hipótesis, no parece que la explicación sea una súbita y ferviente fe —algo francamente improbable conociendo a nuestro personajequizá responda más a su voluntad de involucrarse en las costumbres de la villa o, simplemente, al deseo de asistir como mero observador.

Con todo, y como le ocurriera en Madrid, lo que con mayor frecuencia deja reseñado en su Diario es la relación constante con amigos, las visitas a sus casas («chez Teresica»; «chez Beteta»; «chez Presbitero»; «chez Domínguez»; «chez Tía Matilde»; «chez Mariquita Jabonero»), o las de estos a la suya. Gran cultivador de las relaciones personales y de la conversación, cada temporada añadía a su grupo de amistades nuevos contertulios: el prior del convento del Carmen, el párroco de Hontova, el deán, el presbítero, el boticario, el padre Jacinto, el médico, etcétera. El propio Moratín lo cuenta así en las cartas a su amigo Melón: «[...] pero antes de anochecernos vamos a aquellas eras altas que hay antes de la Cruz de Miranda, y hacemos tertulia Beteta, el Boticario, el Señor Corregidor y algún clérigo $[. .]$.$» .$

Es indudable que Moratín encontró en Pastrana un grupo significativo de personas de ideas ilustradas, o al menos de gran formación, que compartían con él sus inquietudes culturales y que le hacían sentirse bien en su compañía. La amistad profunda con Francisco Fernández Beteta ${ }^{51}$, de quien parece que era familia lejana, se manifiesta en su continua presencia en las anotaciones de su Diario cuando se encuentra en Pastrana, en las que algunos días aparece registrado hasta en tres o cuatro ocasiones, es decir, ocupando la mayor parte del tiempo en actividades conjuntas. No son demasiado extrañas en una misma jornada notas como la del 15 de agosto de 1806: «ici Beteta; baño / ici Beteta; cum il chez Decanus; cum ils ad Val; Beteta ici». También era frecuente que cuando Beteta visitaba la capital se reuniera con Moratín y su círculo: «ici Beteta, Conde and Melón manger ${ }^{52}$. Igualmente es intensa la relación con Teresica, hermana

$51 \quad$ Nacido en Pastrana el 8 de octubre de 1746, pertenecía a una ilustre familia. A su padre, abogado de los Reales Consejos y consejero de la villa, se le debe una interesante Historia de Pastrana. Beteta compartió con Moratín no solo su amistad, también su formación ilustrada. Fue varias veces alcalde mayor de la villa por el estado noble; tras el pronunciamiento de Riego, fue diputado provincial y luego diputado a Cortes. Es un personaje muy interesante al que valdría la pena dedicar un estudio detallado.

$52 \quad$ Diario, pág. 249. 
de Beteta ${ }^{53}$, con la que existía una gran amistad, y posteriormente con su esposo, que nunca aparece reseñado con su propio nombre sino como «vir Teresicae».

Ciertamente, Moratín gozaba en Pastrana de un indispensable círculo de amistades, individuos que hasta 1808 formaban parte de la elite social e intelectual de la villa alcarreña y que compartían con nuestro literato tiempo, diversión, conversación y, presumiblemente (en especial Beteta y el presbítero), ideas ilustradas e ilusiones sobre una España regenerada. Sin embargo, en ese sombrío año de 1808, todos ellos hubieron de adoptar una actitud ante los acontecimientos: la sumisión y el afrancesamiento, o el apoyo incondicional a la guerra contra los franceses, posturas que los desastres terribles de la contienda tornarían irreconciliables.

Moratín fue de aquellos españoles que reconoció la validez del cambio dinástico y colaboró y tuvo cargos en el gobierno del rey intruso. Beteta, por su parte, prestó ayuda directa a los guerrilleros de El Empecinado que merodeaban por los alrededores de Pastrana ${ }^{54}$ y posteriormente fue diputado liberal. El alineamiento en posiciones absolutamente enfrentadas de quienes habían sido tan amigos es un claro reflejo de una triste realidad: una España rota y quebrantada.

En 1814, los franceses perdieron la guerra, el rey abandonó definitivamente Madrid y con él salió el grupo de españoles colaboradores con su gobierno. Entre estos se encontraban Moratín, que inició una vida errante y llena de penurias, Melón y aquellos amigos que lo habían visitado en Pastrana. De la villa sólo le quedaría el recuerdo de «aquella gente bestial» y la eterna amistad de Juan Antonio Melón, colega desde la adolescencia, desde los tiempos en que Moratín trabajaba en el obrador de joyería de su tío (1781), y de la Luisa.

Es obligado pergeñar, en este momento, una sucinta biografía del clérigo Juan Antonio Melón, su eterno amigo. Nacido en Mogaraz (Salamanca) en 1758, su espíritu ilustrado le inclinó tanto a las letras como a las ciencias. Desde instancias oficiales se le encargó la elaboración de una colección de clásicos latinos, lo que le dio la oportunidad de viajar por Europa en busca de los mejores textos. En 1797 vieron la luz, bajo su dirección, las Obras completas de Cicerón (Madrid, Imprenta Real, 14tt.). En 1805 se le nombró juez privativo de Imprentas, cargo desde el que encargó la censura de libros a varios de sus amigos, entre ellos, como no podría ser de otra manera, a Moratín. Como los demás miembros del círculo moratiniano colaboró con el gobierno de José I, por lo que, caído este, hubo de exiliarse, aunque no tardó en regresar a España.

\footnotetext{
53 Se trata de Teresa Fernández Beteta, hermana de Francisco Fernández Beteta e hija del abogado del mismo nombre, prima de Moratín y presumiblemente de alta formación ilustrada.

54 AмP, leg. 132/1809.
} 
Melón había establecido nexos casi familiares con Pastrana a través de Luisa Gómez Carabaño, treinta años menor que él y con la que vivió al menos 43 años. Declarada sobrina adoptiva y heredera y usufructuaria de sus bienes a su muerte ${ }^{55}$, Luisa, nacida en $1788^{56}$ en Pastrana, era hija de Francisco Gómez Carabaño, un pobre garrotero que apenas la podía mantener ${ }^{57}$ (en su correspondencia, varias veces se refiere el dramaturgo al padre de la Luisa). Juan Antonio Melón se hizo cargo de Luisa, cuando esta tan sólo contaba trece años ${ }^{58}$, al tiempo que Moratín lo hacía de su prima Mariquita ${ }^{59}$. Es indudable que Luisa fue amante de Melón y que mantuvo una relación, extremadamente familiar y estrecha, con Moratín.

Junto a Melón, Moratín viviría dos de los momentos más amargos de su vida: su apresamiento en Pastrana, en 1808, y el exilio tras la represión fernandina. Melón y Luisa regresaron a Madrid, no así Moratín, que partió a Bolonia. No volvieron a verse, pero mantuvieron una intensa relación hasta la muerte del dramaturgo. Leandro no dejó nunca de escribir a Melón y siempre encontró palabras cariñosas y pícaras para la Luisa.

En la correspondencia entre ambos, jamás Moratín preguntó por los que habían sido sus amigos y compañeros en sus felices estancias en Pastrana. Sí fueron constantes, en cambio, las referencias a la casa, al cobro de las rentas, a su intención de venderla, etcétera. Jamás preguntó por Beteta, aunque nos consta que se carteó con él al menos hasta 1817, y jamás preguntó por Teresica o Mariquita Jabonero.

Los lazos de Luisa — y por tanto de Melón ${ }^{60}$ — con Pastrana son tan fuertes que, ante el aumento de la represión contra los que habían sido afrancesados, ambos pensaron ir a vivir allí. Moratín trató de disuadir a su amigo y le recordó cómo sus habitantes fueron a prenderlos en 1808. El 18 de septiembre de 1816 le aconsejó: «Si has de estar en España para que te devuelvan tus bienes ${ }^{61}$, no me parece que Pastrana te puede convenir, ni aun a la Luisa tampoco. ¿Qué puedes esperar de aquella gente bestial, que en el mes de junio vino a buscar-

\footnotetext{
55 René Andioc, «El primer testamento de Leandro Moratín y el último de Juan Antonio Melón», en «www.cervantesvirtual.com».

56 Ibid. Se aportan los datos de la partida de bautismo de la niña (Libro de Bautismos B 16, pág. 346).

57 En el Catastro del Marqués de la Ensenada (amp, sig. 223, ff. 106 v.-111 r.), se le cita como de oficio garrotero y sin bienes.

58 Es lógico pensar que en torno a 1801 — año en que adoptó a Luisa- Melón viajaría a Pastrana en más de una ocasión, aunque las notas de su Diario no lo revelen.

59 Diario, pág. 263.

60 En su testamento también beneficia a «[...] Manuela Toledano, vecina de Pastrana, que me ha servido [...]». Vid. ANDIOc, «El primer testamento».

${ }_{61}$ Este había comprado importantes bienes inmuebles pertenecientes a los Bienes Nacionales Desamortizados durante el gobierno de José I y quería recuperarlos.
} 
nos $[\ldots] ? »^{62}$. Con anterioridad, con fecha 17 de enero de 1816 y desde Barcelona, recomienda a Luisa que olvide a su «querida Pastrana»:

[...] Mlle. Louise, je vous salue de tout mon coeur: portez-vous en bien: oubliez toutà-fait votre chère Pastrana [olvide completamente a su querida Pastrana], et tâchez seulement de soigner notre bon ami. Adieu donc: peut-ètre le ciel nous permettra de revoir encore [...].

Finalmente consigue disuadirlos para que abandonen España y se dirijan a París, a donde llegan en 1818. Desde Barcelona, el 13 de julio de 1817, escribe Moratín a Melón:

[...] haz que la Luisa cuide de ti: me alegraré de verla con su gorreta, su devantal [sic], Moratín está imitando el habla popular de Pastrana, con el que posiblemente se expresaba Luisa] de poches y sus chinelas, hablando en francés, y olvidándose por instantes de la algarabía del Albaicín $[\ldots]^{63}$.

Pero, un año después, la Luisa ha vuelto a Pastrana. El 28 de enero de 1819, Moratín continúa en Montpellier y pide a Melón, que parece que está en París:

Darás de mi parte la más cumplida enhorabuena a Mademoiselle Carabagneau, diciéndole cuánto me alegro de ver que se ha logrado el deseo de restituirse a su calle Ancha, a su Albaicín de su alma y a la plaza de los Olmos ¡Con qué alegría la abrazarán el tío Cañaveras, el tío Panchurrín, el tío Canicuta y los demás tíos y tías, y todas las chicas y chicos del lugar, que no tenían otro pío sino el de vella, golver, güena y regusta [sic, nueva imitación del habla popular de Pastrana], y con algunos bienes para socorrer a la pobreza, como es justo y debido [...].

A pesar de mostrar esta alegría por Luisa, el resto de sus epístolas evidencia la amargura y el rencor que el recuerdo de Pastrana le causan. En carta dirigida a su Paquita del 9 de febrero de 1818, le explica: «No escribo a D. Josef, porque le supongo en Alcalá o en Pastrana: mucho deseo que venda o trueque la tal casa, y salga de palurdos; que me parece a mí que con los de su lugar tiene bastante $[\ldots]^{{ }^{64}}$.

62 Obras póstumas, t. II, pág. 262.

63 Barrio de Pastrana en el que vivía la Luisa. Para más información sobre la urbanización, construcción y dedicación de los habitantes del barrio vid. Alegre Carvajal, La Villa Ducal de Pastrana, págs. 134 y ss.

64 Obras póstumas, pág. 307. Se está refiriendo a su amigo José Antonio Conde cuando ya, con motivo de sus nupcias con su sobrina Mariquita, le había regalado la casa de Pastrana. Esta situación duró poco 
Es tan grande —desde 1808- la animosidad que Moratín siente hacia todo lo relativo a Pastrana, que en cuanto consigue que le sea devuelta la propiedad de la casa ${ }^{65}$, tras la confiscación que habían sufrido todos sus bienes al final de la guerra, se la regala a su amigo José Antonio Conde y a su sobrina Mariquita. El 11 de enero de 1817, escribe a su amigo:

No deje usted de ver muy presto a D. Antonio, para que en el caso de que se vaya a Montpellier, le deje a usted el decreto del Rey, por el cual se me devuelve la casa de Pastrana, y además le informe a usted acerca de si se ha comunicado o no la Junta de Secuestro y al Intendente de Guadalajara; pues el no haberme escrito nada Beteta ni el otro, me hace sospechar que todavía no se ha verificado la tal comunicación. Para quedar enterado del paso que lleva, me parece que será bueno que escriba usted a Beteta; yo, esperando carta suya, no le he escrito todavía; pero en el correo siguiente lo haré. Le advertiré al mismo tiempo que saque únicamente de la casa los pocos libros que hay, y unos mapas que están clavados en las paredes. De lo demás nada tengo que disponer. Ustedes harán de su capa un sayo, y concluirán las diligencias que hay que hacer para que se verifique la entrega y posesión de la dicha casa $[\ldots]$.

En 1818 fallece su sobrina Mariquita y, dos años más tarde, su amigo Conde. También muere Beteta, y con él tal vez el último vínculo amable con la villa. A partir de aquí y casi hasta su muerte, Moratín intenta desesperadamente vender esta morada.

Desde su salida de Madrid, nuestro dramaturgo se encontraba en una situación económica precaria y siempre pensó que la venta de sus propiedades en Pastrana podría ayudarle a superarla, aparte de librarle de una preocupación sumamente incómoda. Esto se evidencia claramente en sus misivas. A lo largo de 1821, las alusiones a Pastrana en la correspondencia entre Moratín y Melón son continuas. Desde Barcelona, el 7 de agosto, le comenta a Melón: «Supongo que si vas a fastidiarte a Pastrana, dejarás mis encargos a Silvestre, o a quien te parezca mejor. Dale muchas memorias y dile que le escribiré cuando pueda $[\ldots] »^{66}$. Poco

tiempo ya que en 1818 murió Mariquita de parto y, dos años más tarde, Conde, por lo que la casa revirtió nuevamente a Moratín.

65 En carta a su amigo Conde (Barcelona, 24 de julio de 1816) escribe: «Aún es más gracioso lo que me está sucediendo con la casa de Pastrana: toda la paciencia de los padres capuchinos de la Paciencia no sería bastante para sufrirlo [...]», Epistolario, pág. 161. El 29 de julio recuerda a Melón: «[...] Sigue mi pleito para que me entreguen la casa de Pastrana, que todavía permanece en manos fiscales [...]», Epistolario, pág. 163.

66 Obras póstumas, pág. 365. Esta nota demuestra que las visitas de Melón a Pastrana eran frecuentes y que la relación de Moratín con Silvestre Pérez se alargó hasta la muerte de este gracias a la intermediación de Melón, amigo de ambos. 
después, el 28 de octubre, ya desde Burdeos (ha habido cólera en Barcelona y él ha salido huyendo), le pide a su amigo: «[...] Cuéntame cosas, y dime si viste en Pastrana el palacio encantado, y qué te ha dicho aquella rústica gente, y si tratan de pagar al amo (ahora que ya no es traidor) lo que le deben [...]». Un mes más tarde, el 16 de noviembre, también desde Burdeos le escribe:

Querido Juan: Había empezado a escribir una esquela para que se la enviaras a Lázaro $^{67}$, a fin de que solicitase el cobro de la infeliz rentilla de aquella huerta; pero considerándolo mejor, la he rasgado, y te encargo que nada les digas de esto; porque si se les apura a que suelten dinero y se les amaga con las cuentas atrasadas desde el año ocho, son capaces de quemar la casa $[\ldots]^{68}$.

En la misma carta expresa:

Me alegro de que Luisa haya ido a oler a sus parientes y sacudir las orejas y menear el rabillo por aquellos cerros; pero dile que este lugar (se refiere a París) es mejor que el suyo (Pastrana), y que el río es un poco más ancho, y las calles un si es no más largas, y que las gentes no tienen tantas cerdas en el cogote [...].

También su amiga Paquita Muñoz, que había acudido a Pastrana junto a Moratín en sus mejores años — fue su primer huésped el verano en que estrenó su ansiada casa-, quiso volver allí en sus momentos de máximos apuros económicos. La otrora amada de Moratín, que finalmente había contraído matrimonio con un militar, llevaba una vida difícil, cargada de aprietos y estrecheces.

En dos ocasiones, en correos fechados en 1820 y 1821, encontramos la petición expresa de Paquita de retirarse a vivir a la villa, a la casa del dramaturgo; en ambos casos Moratín la disuadió. Desde Barcelona, el 25 de octubre de 1820, le respondía:

67 Lázaro Francisco Serrano, hijo de su tía Matilde Isabel Pérez, fue administrador de la casa presumiblemente desde 1808. El 9 de junio de 1817 escribe a su sobrina Mariquita: «Me alegro mucho de la remisión de muebles de Pastrana; pues yo temía que dilatándose el ir allá, se desapareciese todo. En cuanto a las cuentas, habrá muchísimos trabajos; saldrán sapos y culebras, y será una Babilonia. En fin tú me escribirás lo que resulte, y sabremos de una vez quién nos ha robado...». En esa misma carta añade a su amigo Conde: «¿Cómo haría usted para trocar la casa de Pastrana por algún olivar, o cañamar, o viña, o cualquier otra cosa que no tuviera techo? Lo que es venderla a dinero contante me parece dificilísimo. En fin, usted verá lo que más convenga. Deseo saber lo que sale a luz de las cuentas de la hortelana...», Epistolario, pág. 182.

68 La situación se repite. El 18 de mayo de 1822, manifiesta: «[...] Me ha escrito Lázaro Serrano, que es mi apoderado en Pastrana años hace, y me dice "Por más cartas que he puesto y puse a su debido tiempo a don Joaquín García Fernández, apoderado que fue del difunto don Josef Antonio Conde, para que viniese a ajustar su cuenta hasta el día en que murió Conde, que fue el 12 de junio, no he conseguido lo verifique [...]"». 
El proyecto de usted de irse a vivir a Pastrana me ha hecho reír, y me persuade que todavía no ha conocido usted bien lo que son los lugareños y los lugares. Mi deseo es que la tal casa se venda trueque de papel de estraza o de aceitunas; pero mientras fuere mía, pueden ustedes usar de ella con entera libertad. Pregunten ustedes a la Luisa en el estado en que está, y se les quitará la gana de ir a ella. Lo que importa es que su marido de usted vuelva bueno y pronto de sus peregrinaciones. Memorias y adiós. La Luisa es una señora de Pastrana [...].

En la correspondencia que ambos mantuvieron más o menos regularmente a lo largo de su vida, en la que Paquita le narraba sus cuitas, se trasluce el innegable tedio, el cansancio, la apatía que Moratín siente hacia lo que esta pobre mujer le cuenta, siempre desgracias, apuros y enfermedades (algo de lo que el propio Moratín estaba sobrado). El resultado más palmario de esta desmotivación es la constante negativa, mediante una sutil disuasión, alegando la irracionalidad de la gente del lugar, a dejarle vivir en su vivienda pastranera. Contrasta esta cruel actitud con la viva correspondencia mantenida con otros amigos, llena de preguntas, encargos y opiniones, y choca de forma sorprendente, con la alegría, la camaradería y el aprecio que emanan aquellas misivas en las que se alude a la Luisa, y con la gracia, la diversión y el profundo interés que le merece cualquier cosa con ella relacionada ${ }^{69}$.

El 2 de febrero de 1821, el problema persiste, Moratín todavía no ha conseguido el propósito de vender su casa y explica a Melón:

No sólo quiero vender la casa de Pastrana, sino que estoy impaciente de que hasta ahora no haya habido ninguno que me haya ofrecido por ella tres pesetas. Escribe enhorabuena al padre de la Luisa, encargándole que haga eficaces diligencias para hallar alguno que entre en ajuste, y ojalá pudiera yo salir de la tal finca $[\ldots]$.

En epístola posterior, del 23 de febrero, leemos: «[...] Bueno sería que el padre de la Luisa hallase algún desesperado que me comprase la casa por la décima parte de lo que me costó; pero será difícil [...]». Desde Gerona, el 30 de agosto del mismo año, en misiva a Melón se refiere al mismo asunto:

Di a doña Pacita que no he querido alquilar la casa de Pastrana, pocos meses ha, a D. Eusebio Domínguez, canónigo de allí, que me la pedía, por la razón que estoy

69 Continuas son las alusiones, en las cartas de Moratín, a los cursos de jardinería que Luisa recibía en el Jardín Botánico. 
esperando venderla de un día a otro; y en este caso tendría que abandonarla cualquier familia que la ocupase. Dile que si han resuelto absolutamente irse a vivir a Pastrana, podrán desde luego irse a vivir a mi casa, mientras hallan otra en lugar que pueda convenirles; pero que si llego a venderla tendrán la incomodidad de salir de ella. En suma, que no la alquilo, sino que la vendo [...].

Posteriormente, en 1823, ante la precaria situación en que se encuentra Paquita, esta por tercera vez insiste en sus deseos de ir a vivir a Pastrana, pero Moratín vuelve a desalentarla ${ }^{70}$. Finalmente, decidió donar la casa con la huerta a la Inclusa o Casa de Expósitos de Madrid, a la que pasó tras su muerte, pero las vicisitudes de la propiedad no terminarían aquí.

Como se infiere de lo hasta ahora expuesto, la agitada, convulsa y violenta época que le tocó vivir a Moratín le impidió gozar con plenitud de sus retiros en Pastrana, tal y como él hubiera deseado y tal y como él planeó y procuró.

Moratín había acudido a su amada Pastrana, a su querida casa, en busca de refugio y paradójicamente es en este apacible retiro, en el lugar más alejado de su querida Alcarria, el paraje denominado el Desierto de Bolarque, donde le alcanzan las iras del populacho que «con podones y trancas» fue a buscarlo. Este violento recuerdo y la humillación de ser detenido y agredido por el vulgo no los olvidó jamás.

Su resentimiento hacia Pastrana y sus gentes se manifiesta continuamente ${ }^{71}$ (incluso se trasluce en las palabras que Melón le dedicaría para la biografía moratiniana que proyectaba Manuel Silvela). Tan sólo desaparece cuando piensa en la Luisa, en los viajes de esta a Pastrana, en su apego a la villa. Es entonces cuando esa amargura se transforma en tierno regocijo.

Incluso ante la tendencia liberal de Luisa, no expresa escepticismo o recelo, únicamente una profunda preocupación. En el mes de abril de 1823, decidida la

70 El 20 de noviembre explica a su amigo Melón: «[...] Si hubiera pensado en conservar la casa de Pastrana, hubiera tenido mucho gusto en que la Pacita y su familia se hubiesen ido a vivir a ella, si les convenía, pero creyendo poderla vender (siquiera por una vigésima parte de lo que me costó) nada he resuelto hasta ahora [...] la he cedido a otros poseedores, que reúnen dos circunstancias muy en su favor: la de ser necesitados e inocentes [se refiere a la Casa de Expósitos de Madrid]. El alquiler de la casa podrá ser de unos doscientos reales al año (sin contar la huerta, porque esta se arrienda separadamente): díselo a la Pacita, por si absolutamente les acomodase ir allí. Pero yo creo que harían muy mal [...]». Moratín, de forma cicatera puesto que conocía la desesperada situación por la que atravesaba su amiga, le quitó la idea de irse a vivir a su casa. Incluso, cuando ya se ha rendido por la imposibilidad de venderla, la cede a una institución benéfica. El dramaturgo ignoró totalmente la necesidad de Paquita, incluso en su testamento donó el retrato que le pintó Goya a la Academia de San Fernando, desposeyendo de él a Paquita.

${ }^{71}$ El disgusto y la aversión de Moratín fue mucho más profundo, no se ciñó solo a Pastrana, sino a toda su vida anterior a su abandono de Madrid. Mientras que, tras un impuesto exilio, uno a uno, sus amigos afrancesados regresaron a España, él no volvió jamás. 
intervención de los Cien Mil Hijos de San Luis para acabar con el gobierno del Trienio Liberal, Moratín pide a Melón:

[...] ponme a los pies de la coronada Luisa, a quien encargo, por los clavos de Dios [expresión seguramente aprendida de la propia Luisa], que no hable de política, ni de los derechos del hombre, ni del equilibrio de poderes, ni de la libertad legal, ni de la soberanía del pueblo, ni de ningún otro artículo de la moderna jerigonza, porque se volverá loca y vivirá rabiando [...].

El 25 de junio siguiente, ante la expulsión del gobierno liberal, escribe: «[...]»Y mi pobre Luisa, ¡qué sustos habrá tenido! ¡Cuánto habrá llorado con la ausencia del uno y la venida del otro! [...]» ${ }^{72}$.

Es tan sólo a través de la figura de su estimada Luisa, de su franco afecto, de su sincera amistad y de su sorprendente camaradería, cómo en el dramaturgo aflora una divertida, fresca y afectuosa mirada hacia su, en otro tiempo, amada Pastrana.

$72 \quad$ Epistolario, pág. 170. 